\title{
Sexual Harassment of Child Brides in India: Case Study of Bathinda District of Punjab
}

\author{
Manpreet Kaur ${ }^{1}$, Mansoor Ahmad Lone ${ }^{2}$
}

\begin{abstract}
Centuries have come, and centuries have gone, but the situations of women have marginally changed. Still they are exploited not only in social spheres but also in household chores. As a women passes through various phases of her life, she undergoes various types of exploitation that not only makes her feel physically and mentally insecure, but also decreases herself worthiness by manifold. The objective of this study is to bring to the surface the sexual exploitation of child brides. Child marriage and after that sexual abuse of child brides is one of the ways in which women are sexually harassed by their partners even the sexual harassment is a crime under section 509 IPC. Through this paper, the sexual harassment of child brides highlighted. The study is a humble attempt to recommend some measures to stop child marriages and sexual abuse of the child bridel marital rape cases. For this purpose, case studies from Bathinda District of Punjab have been collected and evaluated. The paper tries to evaluate the legislative measures against the two activities such as child marriage and sexual abuse of child brides. Thus this paper is of an immense important for women empowerment as it creates awareness among the people on the issue and bring to the kind notice that the sexual harassment of child brides is crime and it should be stopped.
\end{abstract}

Keywords: Women, sexual harassment, child marriage, exploitation.

\section{Introduction}

A female child grows up with a continuous sense of being weak and in need to protection, whether physical, social or economic. The helplessness has led to her exploitation at almost every stage of her life. Women face common challenges around the world. However the challenges are many due to the circumstances in which they live. Some of these are owing to early marriage, low literacy rates, overwork, low social status, and food allocation, limited choices in decision-making, sexual harassment and violence against women. Age at marriage is one such factor which, directly or indirectly, affects all aspects of her life (Rajeshwari, 2012).

Child marriage impacts girls in greater number and constitute a grave threat to young girls lives and future prospects. It is a human rights violation that denies a girl of her childhood, disrupts her education, limits her opportunities, increase her risk violence and abuse, jeopardizes her health (Loaiza, 2012).Child marriage is not only a violation of a girl's rights; it also seriously compromises efforts to reduce gender based violence, advance education, overcome poverty and improve health indicators for girls and women. When a girl is denied her basic primary education and forced to marry young, her personal development is stunted. She is left with few - if any - negotiation skills and therefore has limited decision-making power in her new household. Child marriage also deprives a girl of the valuable and necessary skills required to enter the labour market, therefore denying her the opportunity to help lift herself - and her family - out of poverty. In short, pulling girls out of school and forcing them into early marriage ensures that poverty will be handed down from a mother to her daughter, and family to family, for generations to come. For both girls and boys, child marriage has profound physical, intellectual, psychological and emotional impacts, cutting of educational opportunity and chances of personal growth. In addition for girls, it will certainly mean premature pregnancy and child bearing.

\subsection{Child marriage in India}

Child marriage has been prevalent in India and continues to these days. Historically, young girls would live with their parents till they reached puberty. In the past, the child widows were condemned to a life of great agony, shaving heads, living in isolation, and shunned by the society. Although child marriage was outlawed in 1860 , it is still a common practice. According to UNICEF's state of the "World's Childern-2009" report, 47\% of India's women aged 20-24 were married before the legal age of 18, with 56\% in rural areas. The report also showed that $40 \%$ of the world's child marriages occur in India (Santhya, et al., 2010). But it is very difficult to get accurate data on the true extent of child marriages in India. This is because most marriages are not officially registered, and many parents resort to falsifying girl's ages.

\footnotetext{
${ }^{1}$ Research Scholar, South and central Asian Studies Department, Central University of Punjab, Bathinda, India

${ }^{2}$ Research Scholar, South and central Asian Studies Department, Central University of Punjab, Bathinda, India. 


\subsection{Child Marriage in Punjab}

Child marriages are also held in Punjab. There are various reasons behind the early marriage of girl children in Punjab. Illiteracy and backwardness of rural Punjab make the parents of girls worried about the marriage plans of their respective daughters. Some social evils like dowry, low economic resources, and lack of fertile land made the parents worried. They don't want to spend too much on girl's education rather than this they preferred to marry them earlier. So the phenomenon of child marriage is linked to poverty, illiteracy, dowry, landlessness and other such social evils.

\subsection{Sexual Harassment}

Sexual harassment is behaviour; it is defined as unwelcome behaviour of a sexual nature. Sexual harassment can have a ripple effect in various areas, negatively affecting women's and girls' access to education, ability to move about freely in society, ability to work outside the home, freedom of dress and speech, and ability to avoid early marriage. The link between sexual harassment and child marriage is underexplored. As one report by the United Nations Population fund (UNFPA) stated that child marriage is often seen as a safeguard against premarital sex, and the duty to protect girl from sexual harassment and violence is transferred from father to husband.

Marriage is seen as a preventative measure to protect young girls from potential danger. Indeed parents may push underage daughters into early marriage to help escape the aggravations caused by sexual harassment and may believe that if their daughter has husband they will be saved from such dangers. They forget about the fact that their husband may be the reason of their sexual harassment after marriage. There are so many cases of sexual harassment recorded where the criminal are mostly belongs to the victims in India. Child marriage and after that sexual abuse of child brides is one of the ways in which women are sexually harassed by their partners even the sexual harassment is a crime under section 509 IPC. Following table describes the rape victim and accused relationships;

Table 1.1 Rape victim and accused relationship- 2012

\begin{tabular}{|l|l|l|l|}
\hline Sl. No & Accused relationship & No of rape victims & \% of rape victim \\
\hline 1 & Neighbours & 207 & $29.32 \%$ \\
\hline 2 & Friends & 200 & $28.32 \%$ \\
\hline 3 & Relatives & 59 & $08.35 \%$ \\
\hline 4 & Employers/ co-workers & 17 & $02.41 \%$ \\
\hline 5 & Other known persons & 197 & $27.90 \%$ \\
\hline 6 & Unknown/ stranger & 26 & $03.68 \%$ \\
\hline & Total & $\mathbf{7 0 6}$ & $\mathbf{9 9 . 9 8 \%}$ \\
\hline
\end{tabular}

Source: Delhi Police (The Hindustan news Staff Reporter New Delhi, January 19, 2013)

Table 1.1 shows that maximum number of rape victim was committed by the known persons such as Neighbours, friends, relatives and known persons. Only $3.68 \%$ cases were committed by the unknown persons. According to the above data known persons are mostly responsible for the crime (especially sexual harassment and rape) against women rather than unknown persons.

\subsection{Sexual Harassment of Child Brides}

Women's rights and well-beings are under threat all the time, either within the family or outsides its confines. Several studies indicate that child marriage makes young wives extremely vulnerable to physical, sexual, psychological and economic abuse (Chakravarti et al., 2013). There is some empirical evidence that child marriage is associated with increased risk of girl's experiencing domestic violence and sexual abuse. An International Centre for Research on Women (ICRW) survey in the states of Bihar and Jharkhand, India, in 2004, found that girls, who were married before 18 were twice as likely to report being beaten, slapped or threatened by their husbands than girls who married later. They were also three times as likely to report being forced to have sex without their consent in the previous six months (Hussain \& Khan, 2008).

The Indian legal system does not recognise rape within marriage. Section 375 of the IPC mentions as an exception: "Sexual intercourse by a man with his wife, the wife not being under 15 years of age, is not rape." According to Section 376, the rapist should be punished with imprisonment for at least seven years, which may extend to a 10 years term or even life-term. The legal age for marriage for girls in India is 18 years and the law protects girls only up the age of 16 . Marital rape should be covered under the definition of rape. The law does not treat marital rape as a crime. Even if it does, the issue of penalty remains lost in a cloud of legal uncertainty (Gupta \& Gupta, 2013). The legal system must be forced to accept rape within marriage as a crime. 
In 2005, the Protection of Women from Domestic Violence Act, 2005 was passed which although did not consider marital rape as a crime, did consider it as a form of domestic violence ${ }^{3}$. Under this Act, if a woman has undergone marital rape, she can go to court and obtain judicial separation from her husband. This is only piecemeal legislation and much more needs to be done by the Parliament in regard to marital rape or sexual abuse of child brides.

\section{Legal Rights Related To Sexual Harassment}

Sexual Harassment infringes the fundamental right of a woman to gender equality under Article 14 of the constitution of India and her right to life and live with dignity under Article 21 of the Constitution which includes a right to a safe environment free from sexual harassment. The right to protection from sexual harassment and the right to work with dignity are recognised as universal human rights by the international conventions and instruments such as Convention on the Elimination of all Forms of Discrimination against women (CEDAW) which has been ratified by the Government of India ${ }^{4}$.

But there is not any specific law for the child brides and married women for their protection from sexual harassment by their husbands in their homes.

\section{A Case Study of Bathinda District of Punjab}

Bathinda is a historical and important district of Punjab. It is associated with the imprisonment of Razia Sultana in the fort, which is more than 1800 years old. Bathinda is a city of lakes, the industrious farmers of the district have changed the profile of the district from a desert to thriving green fields and made it one of the leading agriculture district. Research has been carried out in Central University of Punjab, Bathinda. Primary data related to research has been collected from the victims of child marriage in Bathinda district. The field study has been conducted in rural areas as main villages (Deon, Bhokhra, Gill Patti, Bir Talab, Naruana, Jai Sing Wala, Khialiwala, Joganand, Mehta, Jassi Pou Wali, Bahoo, Gehri, etc.) in Bathinda district and urban areas (Bhucho Mandi, Maur Mandi and Bathinda city) of Bathinda district.

\subsection{Data Collection}

The research is deductive in nature, as primary as well as secondary data have been collected for this purpose. Primary data has been collected through the medium of interview and group discussion methods. The interview schedule was prepared and Snow ball sampling method has been carried on women aged 20-30 who were married at the age of below 18 years. 80 of these under aged married women have been interviewed for this purpose. Secondary data have been collected through books, publications, journals, articles, essays etc. For more information interview with, Punjab Istri Sabha's President, member of Punjab Istri Sabha of Bathinda district also has been carried.

\subsection{Sampling}

The study utilises the 'Snow-Ball Sampling' method and for this purpose primary data has been collected from child marriage victims of the rural as well as urban areas of the Bathinda District of Punjab. And from each area (rural and urban) 40-40 child marriage victims have been identified. These victims are from both rural and urban backgrounds. Special attention has been paid to selecting individuals with diverse economic, social, ethnic, and cultural backgrounds.

From the field survey collected data describes that 62.5 percent women has been forced by their partner to intercourse, and from which above 50 percent feel extremely uncomfortable because of their partner's requests. 82.5 percent of women afraid to say no to their partners because of the fear of domestic violence. Only 10 percent women felt sexually harassed by their partner and 62.5 percent of women have felt that their first intercourse was without consent from which 37.5 percent felt physically hurt during intercourse. These types of sexual abuse are not only the result of partners feeling of dominance but also the result of the addictions of alcohol or drugs of partner. In rural areas, 30 percent of women are forced by their partner and among these women, 25 percent of women face physical hurt during intercourse. Majority $(52.5 \%)$ of women are afraid to say no to their partners because of the fear of domestic violence. But in rural areas women do not feel that they are sexually harassed by their partner, because they think that it is a duty of women to satisfy their partner, and

\footnotetext{
${ }^{3}$ The Protection of Women from Domestic Violence Act, 2005, Section 3 Explanation 1 (ii).

${ }^{4}$ Available at: http://ncw.nic.in/PDFFiles/sexualharassmentatworkplacebill2005_Revised.pdf accessed on 15 April 2014.

${ }^{5}$ A snowball sample is a non-probability sampling technique that is appropriate to use in research when the members of a population are difficult to locate. A snowball sample is one in which the researcher collects data on the few members of the target population he or she can locate, then asks those individuals to provide information needed to locate other members of that population whom they know.
} 
do as their partner want. Only 2.5 percent respondent accepts that their first intercourse was without her consent, and 17.5 percent respondents accept that their first intercourse was violent.

\section{Comparison Of Sexual Abuse Of Rural \& Urban Child Brides}

The concept of sexual abuse is completely unknown to the respondents. In rural areas, women think that it is their duty to fulfil all the desires of their husband and for their husband they should always be available irrespective of their health conditions. Only 17.5 percent women respondents agreed on the fact that their first intercourse with their partner was violent as compare to 42.5 percent in urban areas. In rural areas, 52.5 percent respondents are accepted that we cannot refuse our husband to intercourse, because of the fear of domestic violence as compare to 82.5 percent in urban areas. In urban areas 62.5 percent women felt that they are forced by their partner as compare to 30 percent in rural areas.

Figure 4.1

\section{Comparison of Sexual abuse of child brides in rural \& urban Bathinda}

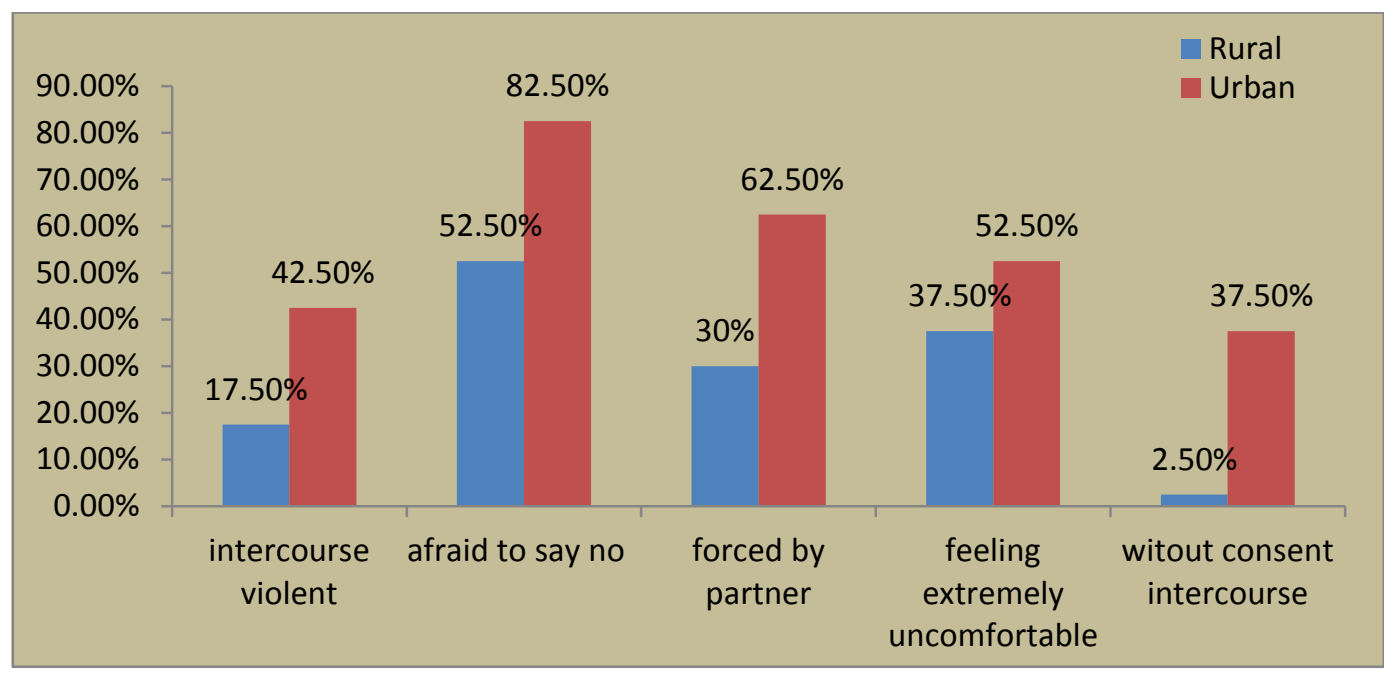

In urban areas 52.5 percent respondents felt that they feel extremely uncomfortable during intercourse with their partner as compare to 37.5 percent of respondents in rural areas. In rural areas women still feel that their husbands are like their Gods, and without their husbands there is no life for women in society. They think that we should follow our husband and do as they want. Husband can physically, mentally, emotionally and sexually abuse them because they are meant for their husbands and they do not say no to their husbands. Only 2.5 percent respondents in rural areas accepted that their first intercourse was without consent as compare to 37.5 percent respondents in urban areas.

From the primary survey, various types of reasons highlights that contributes to the continuous sexual abuse of child brides in Bathinda district.

\section{Male subjugated social environment}

As a male subjugated society men in all sphere of their life dominate the women of Indian Subcontinent. In her life cycle a women depends on father, brother, husband and lastly their sons. Besides, they are dominated and oppressed in every sector by the male members. Owing to such dependency, the male members think that they always direct women and all services should be centred to the interest of the male. Because of this thinking men always dominated on their younger wives.

\section{Socio-Economic reasons}

The disruption in the traditional rural economic pattern brought about by changing socio-economic processes has adverse effects on women. Both the economically and socially they are vulnerable in the society. Traditional socio-cultural practices, low rate of education, lack of employment opportunity, and low nutritional and health status etc. are some of the factors responsible for holding low social and economic status, unemployment have increased the stress and tension in male-female relation in poor households and given rise to desertion, divorce and violence. 


\section{Cultural Ideological impact}

Irrespective of national prosperity or level of development, women are vulnerable to exploitation, oppression and all other types of open violence from men in all societies where cultural norms, tradition and legal system sanction women's subordination to men. In India, an important mechanism of male dominance is the proliferation of gender ideology through sanctions of religious texts and their gender-selective interpretation by the community leaders. Moreover, increasing exposure to violence through popular reading, theatres, film and TV shows, satellite culture etc. directly or indirectly encourage men to commit offences like rape within the chores of their house as well as outside the house.

\section{Poverty commonness:}

Most people of the country are often victimized of due to object poverty. People in large number are living in rural areas. Majority of people are living below the poverty line. They live from hand to mouth. Because of poverty they have to marry their children earlier and they also want to escape from their educational expenditure. This results as a continuous exploitation of their girl children in their own home.

\section{Recommendations}

Early marriage of girls is socially valued and is a widespread practice in India. Despite the existence of national treaties and laws, child marriage continues to be pervasive in the region, particularly in the Jharkhand, Rajasthan and Andhra Pradesh. Clearly, there is a need for effective policies and programs to eliminate child marriage. Key priorities recommended for national and state governments are as follows:

\subsection{Strengthen the legal framework and law enforcement}

Although all the South Asian countries have adopted laws to prevent child marriage, the absence of a uniform law establishing a minimum legal age of marriage of at least 18 for girls, lack of awareness and enforcement remain the biggest challenges as child marriage practices continue unabated. Address gaps and inconsistencies in existing laws and, in accordance with international laws, establish a uniform minimum legal age at marriage of at least 18 for girls. Ensure severe punishment for violators of the law, for this, identify and prosecute all parties involved in child marriage so that the law becomes a restriction. Also, increase penalties in countries where they are currently low. Create awareness among public and duty bearers i.e. government and law enforcement officials on girls' legal rights to be free from child marriage and protected from violations of their reproductive rights and sexual violence resulting from the practice. In addition create/raise awareness among girls on possible legal options for avoiding or leaving a child marriage. Conduct comprehensive training programs: Inform law enforcement officials, registrars, judiciary officials and religious leaders about the negative impacts of child marriage especially in high-risk and poverty-stricken areas where child marriage is rampant and their role in its prevention. Enlarge public campaigns to increase awareness of the laws and punishments associated with the practice. Strengthen essential registration systems to improve the birth and marriage registration systems to better prove a girl's age at marriage. It is important to make people understand the value of birth registration which ensures rights to entitlement for the child in the long run. At the same time birth registration ensures better implementation of the laws including child marriage prevention laws besides providing legal rights to the child. Develop and strengthen effective child protection mechanisms, including community based child protection systems.

\subsection{Increase Educational Opportunities for Girls}

Providing education especially at the secondary level to girls is a key strategy for eliminating child marriage. Girls who marry early often dump formal education. To keep girls in school, parents and girls need greater assurances about the quality, safety and value of continued education. Families also need financial incentives to make education affordable, particularly for secondary and tertiary education in which enrolment lags far behind that of primary education in the region. While achievements have been made in primary education girls' enrolment across many South Asian countries in secondary and tertiary enrolments lags behind.

Allocation of sufficient resources from national and state budgets to ensure quality education at all levels for girls. Provide incentives to girls from economically impoverished families by offering conditional cash transfers or scholarships for secondary education to financially disadvantaged girls to continue their education. Make schools more attractive to girls and their parents by making schools and surrounding safe, providing secure and clean toilets, having more women teachers and improving overall school quality. Promote education for married adolescent: Promote the re-enrolment of girls who have dropped out of school so that they can continue and complete at least their secondary education. 


\subsection{Provide Life Skills Training and Reproductive Health Education and Services}

Early marriage and adolescent child bearing create serious consequences to girls' health and development. Life skills education that engages girls, their families and communities can play a role in delaying marriage. Sexual and reproductive health information and services also are important for adolescent girls, especially in supporting those who are already married.

Include a focus on life skills, sexual and reproductive health and rights in school curricula. Train teachers or special staff to undertake discussions with students about relationships, gender discrimination, contraception and maternal and neo-natal health. Promote adolescent girls' access to sexual and reproductive health information and services through government as well as Non-Governmental Organisation (NGO) initiatives. Improve health systems by training to health providers to provide information regarding sexual and reproductive health issues to adolescent girls. Gender-sensitive health policies, standards, and protocols should also be put in place.

\subsection{Invest in Programs that Economically Empower Young Women and Girls}

Programs that build girls' financial literacy and income generating skills can have a positive impact on preventing early marriage in India. Support market-oriented interventions that economically empower girls and women; such interventions should be at both the national and local levels, and should prioritize girls and women in marginalized communities with a high prevalence of child marriage.

\subsection{Enhance Safety in Public Areas}

Young women and girls live in danger of sexual harassment and violence in many public places. The risk of sexual harassment and rape forces parents to marry off their daughters at an early age, before they lose their virginity (ICRW, 2013)

Make public areas safer for women and girls. Provide safe transport facilities for girls to reach school safely. Create safe areas for women and girls especially during humanitarian emergencies. Establish user friendly help lines for girls and women to report and seek help in instances of abuse and violence. Sensitize law enforcers and the public about the importance of safety for women and girls. Engage with Men and Boys in Preventing Child Marriage Working with boys and men can be a promising strategy in child marriage prevention. A study in India found that boys could be successfully trained as educators and advocates for delaying marriage among girls (Gupta et al, 2008, ICRW).

Young boys and girls who articulate their views on marriage and education with clarity and maturity are often able to persuade their parents to prevent child marriage. Therefore it is important to provide young boys and girls with knowledge and information about health, education and their rights regarding child marriage, and also build their capacities and equip them with confidence so that they become ambassadors of child rights in their community.

World Vision is working with men and boys in India to challenge the beliefs and behaviours of fathers, sons, husbands and brothers as they have the capacity to influence harmful practices in their communities. Engage men to challenge traditional gender norms and roles and address gender inequity. Better understand the perspectives of married young men on child marriage. To engage men and boys as advocates against child marriage, it is important to understand the experiences and attitudes of young men who marry early to underage girls. Strengthen capacities and empower boys and girls in the community: Platforms should be created at the community level to educated young boys and girls regarding negative consequences of child marriage and discuss issues and concerns regarding sexuality.

\subsection{Address the Needs of Married Girls}

There are limited public and civil society programs that exist to meet the needs of married adolescents. In order to protect married adolescent girls from health and social vulnerabilities, it is essential to provide measures specifically designed and targeted towards them.

Amend laws which prevent married and or pregnant girls from attending school. Increased support for girls to go back to schools after marriage or child bearing. Make programs and services available to married girls. These include sexual and reproductive health, life skills and livelihoods interventions. Increase community awareness and education campaigns to stress the value of completing secondary education for married girls.

\subsection{Increase the Value of the Girl Child}

Girls are traditionally undervalued and discriminated against in India. The low social value placed on daughters is due to structural gender inequities that result in lack of access to educational and employment opportunities for girls in comparison with boys. In order to enhance the value of girls and women in society it is crucial to address the root cause of such inequalities by pressing for equal opportunities for girls. Provide equal opportunities for girls in education, employment, and access to safe public spaces. Showcase positive girl role 
models. Support public campaigns, and engage with parents, local leaders, and government officials to discuss and promote positive girl role models from the community and society.

\section{Conclusion}

Child marriage is a violation of human rights whether it happens to a girl or a boy, but it represents perhaps the most prevalent form of sexual abuse and exploitation of girls. Girls are traditionally undervalued and discriminated against in India. The low social value placed on daughters is due to structural gender inequities that result in lack of access to educational and employment opportunities for girls in comparison with boys. In order to enhance the value of girls and women in society it is crucial to address the root cause of such inequalities by pressing for equal opportunities for girls. Provide equal opportunities for girls in education, employment, and access to safe public spaces.

There should be a need of a legislatives step that protects the child brides and women from sexual harassment in their own homes by their own partners. Marital rape should be considered as a crime and there should be a strict provisions and punishment for the criminals, who sexual abused their partners. Efforts also must be made to create gender equitable norms and practices that value girls' education, employability, earning potential and positive sexual and reproductive health outcomes. There is a need to acknowledge women as a human being, away from the notion of her being a mere chattel, and give her respect and dignity she deserves.

\section{References}

[1]. Rajeshwari. (2012, November 5) Woes of Women- age at marriage is one such factor which affects all aspects of a woman's life' Daily Post Newspaper. Delhi.

[2]. Loaiza, E. (2012) Marrying Too Young End Child Marriage, New York: United Nations Population Fund.

[3]. Santhya, K. G., Ram, U., Acharya, R., Jejeebhoy, S. J., Ram, F., \& Singh, A. (2010). Associations Between Early Marriage and Young Women 's Marital and Reproductive Health Outcomes : Evidence from India. International Perspectives on Sexual and Reproductive Health, 36(3), 132-139.

[4]. Delhi Police: The Hindustan news Staff Reporter New Delhi, January 19, 2013.

[5]. Chakravarti, U., Batalia, U., Baxi, P., Barbora, X., \& Tellis, A. (2007), Rape Culture. Economic and Political Weekly, $42(50), 4$.

[6]. Hussain, R., \& Khan, A. (2008). Women's perceptions and experiences of sexual violence in marital relationships and its effect on reproductive health. Health Care for Women International, 29(5), 468-483. Doi: 10.1080/07399330801949541.

[7]. Gupta, D. B., \& Gupta, D. M. (2013). Marital Rape : - Current Legal Framework in India and the Need for Change Marital Rape An Understanding. Galgotias Journal of Legal Studies, 1(1), 1-17.

[8]. http://ncw.nic.in/PDFFiles/sexualharassmentatworkplacebill2005_Revised.pdf accessed on 15 April 2014.

[9]. ICRW, (2013) Asia Child Marriage Initiative: Summary of Research in Bangladesh, India and Nepal, International Center for Research on women. 